\title{
Civilian deaths from weapons used in the Syrian conflict
}

The ongoing Syrian conflict is one of the largest humanitarian crises of the 21st century so far. Debarati Guha-Sapir and colleagues analyse the impact of weapons on civilian deaths, with a focus on women and children

Debarati Guha-Sapir professor of disaster epidemiology ${ }^{1}$, Jose M Rodriguez-Llanes epidemiologist, research fellow ${ }^{1}$, Madelyn H Hicks associate professor ${ }^{2}$, Anne-Françoise Donneau biostatistician ${ }^{3}$, Adam Coutts public health policy specialist, honorary research fellow ${ }^{4}$, Louis Lillywhite senior consulting fellow, retired lieutenant general ${ }^{5}$, Fouad M Fouad assistant research professor of public health $^{6}$

${ }^{1}$ Centre for Research on the Epidemiology of Disasters, Institute of Health and Society, Université Catholique de Louvain, Brussels, Belgium; ${ }^{2}$ Department of Psychiatry, University of Massachusetts Medical School, Worcester, MA, USA; ${ }^{3}$ Department of Public Health, University of Liège, Liège, Belgium; ${ }^{4}$ Department of Politics and International Studies (POLIS), University of Cambridge, UK; ${ }^{5}$ Chatham House Centre for Global Health Security, London, UK; ${ }^{6}$ Department of Epidemiology and Population Health, Faculty of Health Sciences, American University of Beirut, Lebanon

What started as a peaceful uprising in Syria in March 2011 escalated quickly to an armed conflict. By 2012 conflict had become the leading cause of death of Syrians. ${ }^{1}$ Health systems have been reshaped, now being separated into areas controlled by the government, the opposition, or self proclaimed Islamic State factions-we group the last two as non-state armed groups (NSAG; fig $1 \Downarrow$ ). These areas differ vastly in terms of service delivery capacity, number of trained staff, and access to essential medicines. ${ }^{2}$

Indirect conflict related deaths have arisen from poor sanitation and severe disruption to Syria's healthcare system. ${ }^{3-5}$ In December 2014, 20\% of Syria's public hospitals were completely non-functional, and another $35 \%$ provided only partial services. ${ }^{4}$ Direct conflict related deaths are those that are caused by weapons and other violent methods used in warfare. In this article we assess the direct conflict related deaths (hereafter termed violent deaths) of women and children among civilians killed in the Syrian conflict, because they are identified as vulnerable populations in public health and under specific laws of war such as the Geneva Conventions..$^{6-9}$

\section{War related deaths in Syria}

Violent deaths have been considerable in Syria. A report commissioned by the United Nations found that from March 2011 to April 2014 over 191369 verifiable violent deaths of individuals had occurred, including both combatants and civilians. Individuals were identified by their name and the date and location of their death, thus representing the minimum number of violent deaths from the Syrian conflict at the time. ${ }^{10}$ Population surveys can provide estimates of overall deaths and excess fatalities in a war. ${ }^{11-14}$ But epidemiological analyses of war deaths from specific weapon types have been hampered by small sample sizes and uncertainties that limit their usefulness. Associations between weapon types and victim characteristics in armed civil conflicts are not well understood and are rarely studied. ${ }^{15}{ }^{16}$ Individual records of violent deaths and their causes are difficult to obtain from death registration systems as they progressively lose functionality or become unreliable in conflict. ${ }^{11-18}$ Human rights groups and non-governmental organisations have produced large, detailed registries of individual violent deaths based on systematic collation of media reports ${ }^{15}$ and data on casualties collected by volunteers on the ground, as in Syria. ${ }^{10}{ }^{19}$ Such detailed, individualised data can provide useful insights into weapon associated patterns of deaths.

Four groups have provided ongoing documentation of verifiable and identifiable violent deaths in the Syrian conflict: the Syrian Center for Statistics and Research, the Syrian Network for Human Rights, the Syrian Observatory for Human Rights, and the Violations Documentation Center in Syria (VDC). These have provided the majority of data used by the UN Office of the Commission for Human Rights. ${ }^{10}$ However, VDC is the only 
one of the four to identify whether each death is that of a civilian or a combatant. Distinguishing between the two, and identifying the means by which they are killed, can aid the assessment of possible human rights breaches. It can increase understanding of the nature and practices of a war, inform improved civilian protection, and identify demographic groups that are particularly vulnerable to the different types of weapons used in a war. ${ }^{6}{ }^{15}$ The VDC considers any member of any NSAG or of the Syrian Army to be a non-civilian. ${ }^{20}$

We used VDC data to examine 78769 civilian violent deaths that occurred in Syria from 18 March 2011 to 21 January 2015 for associations between weapon types and demographic groups. Of these deaths, 77646 were in NSAG controlled areas and 1123 in government controlled areas (see appendix A on thebmj.com for a full description of our methods). Although the majority of deaths were of men, nearly $25 \%$ of Syrian civilians killed were women and children (see tables B1 and B2 in appendix on thebmj.com).

\section{Trends and patterns in weapon related deaths}

In NSAG controlled areas, time trends of cumulative deaths by weapon types indicate an increase in the use of shelling (which in the VDC database includes artillery and tank shells, mortars, rocket launchers, and ground launched missiles), air

bombardments, shooting, and executions around the middle of 2012. Of these, shelling claimed the largest number of civilian lives. A notable rise in deaths caused by air bombardments also occurred towards the end of 2013 (fig $2 \Downarrow$ ). A total of 969 (1.2\%) deaths reported in NSAG controlled areas and zero deaths in government controlled areas were caused by chemical weapons (tables B1 and B2).

\section{High proportion of children are dying}

Over $16 \%$ of the civilians who died violently in NSAG controlled areas and over $23 \%$ of those who died in government controlled areas were children. Children in NSAG controlled areas were largely victims of shelling and air bombardments ( $75 \%$ of total, $n=9368$ ) - mainly by the government. By contrast, no child deaths from air bombardments (potentially from NSAG) were reported in government controlled areas, where nearly two thirds of children died from shells alone $(n=175)$. The proportion of deaths of children caused by ground level explosives in NSAG controlled areas was small-3.2\% $(n=395)$ compared with $25.7 \%(n=69)$ in government controlled areas.

The government and rebel factions in Syria typically claim that the targets of their bombs and shells are enemy combatant strongholds, but our findings indicate that for Syrian children these are the weapons most likely to cause death. Children who died in the Iraq war were also most likely to have been killed by bombs or shells. ${ }^{6}{ }^{15}$ Conversely, the impact of bombs and explosives on children in the Croatian war (1991-5) was much more limited, and female deaths were rare. ${ }^{17}$ The vast majority of deaths of children in the Croatian war were caused by firearms $(99.2 \%)$.

Because children in the Syrian conflict are generally not in a combatant role, the high proportion of children among victims of explosive weapons may signal possible disproportionate or indiscriminate behaviour or weapons. ${ }^{6-23}$ It could also be the result of the intentional targeting of civilian dwellings and areas likely to contain high proportions of children.

\section{Weapon types and deaths of civilians}

In both NSAG and government controlled areas, we found that the likelihoods of death were significantly higher for children than for men for air bombardments, shells, ground level explosives, and chemical weapons (fig $3 \mathrm{~A} \Downarrow$ ). We found the same pattern for women with the exception of ground level explosives (fig 3B $\Downarrow$; table B3 in appendix on thebmj.com). Child deaths caused by ground level explosives were more than two times higher in government controlled areas (OR 5.00, 95\% confidence interval 2.85 to $8.79 ; \mathrm{P}<0.0001)$ than NSAG controlled areas $(1.85,1.63$ to $2.10 ; \mathrm{P}<0.0001)$.

The targeting of children by suicide bombs (in the ground level explosives category) has been documented in Syria. ${ }^{18}$ Therefore it cannot be assumed that deaths of women and children from large area explosive weapons are always from the indiscriminate nature of the explosion affecting anyone in the area. The examples of suicide bombing of children at schools (by unknown perpetrators) and of barrel bombs being dropped by helicopters repeatedly over hospitals by government forces indicate that indiscriminate weapons can be used in a targeted manner against children and other civilian groups. ${ }^{5}$

Execution is the most individually targeted form of death in a conflict. Although 852 children were killed by execution, including execution after torture, in NSAG controlled areas, children were significantly less likely than men to be killed by execution, compared with shootings (fig 3A; table B3).

Women were significantly more likely to die from chemical intoxication (4.72 (3.93 to 5.67)) than men, as were children (2.11, 1.69 to 2.63). Our findings indicate that the use of chemical weapons in NSAG controlled areas was particularly harmful to women and children and that the partial destruction of chemical weapons after mid-2012 probably saved many lives.

Air bombardments $(2.16,1.99$ to $2.35 ; \mathrm{P}<0.0001)$ and shelling $(1.99,1.86$ to $2.14 ; \mathrm{P}<0.0001)$ presented the second and third most likely cause of death for women victims after chemical weapons (fig 3B). There was no significant difference in the odds of death from ground level explosions between women and men in either government controlled (1.76, 0.93 to 3.36; $\mathrm{P}=0.084)$ or NSAG controlled areas $(0.91,0.76$ to 1.08 ; $\mathrm{P}=0.283$ ).

For children, on the other hand, deaths caused by air bombardments or shelling were even more likely than those caused by chemical weapons. Ground level explosives were similarly likely to cause the death of children as chemical weapons in this war. Although chemical weapons are an international target for control and destruction, air launched bombs and shells, which are at least equally and in our analyses probably more lethal (for children in particular), remain without effective sanction.

\section{Children had higher odds than women}

In NSAG controlled areas, the odds of death were significantly higher for children than women for all explosive weapons: 1.47 times higher for air bombardments (95\% CI 1.33 to 1.63), 1.31 times higher for shelling (1.20 to 1.43), and 2.04 times higher for ground level explosives (1.67 to 2.49). The odds of death by chemical weapons were lower for children than women (OR $0.45,0.35$ to 0.57 ). The odds of death by execution did not differ between children and women (fig $4 \Downarrow$; table B3). In government controlled areas, the odds of death by ground level explosives were 2.83 times higher for children than women (1.31 to 6.11; $\mathrm{P}=0.008$ ) but were not significantly different for shelling (1.11, 0.55 to $2.22 ; \mathrm{P}=0.78$ ). This finding suggests that children are 
being targeted in places where they are more concentrated, such as schools, or that they are more susceptible to these explosions, as indicated by higher death to injury ratios from comparable weapons in the Iraq war. ${ }^{24}$

\section{Conclusions}

We found evidence that children and women had higher odds of death by explosive weapons and chemical weaponry, relative to shootings and compared with civilian men. Explosive weapons were most lethal among children compared with both civilian men and women. On the other hand, civilian men constituted the largest share of the civilian death toll, mostly being killed by shells, shootings, and executions.

Other studies of direct deaths from weapons in the Syrian conflict have examined their impact on children. ${ }^{19}$ However, to our knowledge this is the only study at the time of writing that examines and compares violent deaths from different weapons in civilian children, women, and men. In addition, our study uses measures of association in a modelling framework to ascertain the relative impact of these weapons on causing deaths in these different civilian groups (see appendix on thebmj.com for a full discussion of the strengths and limitations of our study).

The unanimously adopted resolution 2139 by the UN Security Council in February 2014 states that access to humanitarian aid should be increased for Syrians, attacks against civilians should be ceased, and sieges of populated areas should be lifted. Our findings show the ongoing, severe impact of war on the deaths of children, women, and men in the civilian population related to the continued disregard of these resolutions. ${ }^{25}$ Our analysis indicates that using explosive weapons in populated areas in Syria has disproportionately lethal effects on women and children and should be urgently prohibited. Given the mortality burden of weapons on children and women in Syria, active measures to stem the flow of heavy armaments to all sides in the Syrian conflict are a possible way to cease hostilities. This was a major lesson learnt from the Lebanese civil war when the import of heavy weapons was stopped by outside powers and should be used now.

Acknowledgements: We thank VDC for providing data clarifications; CRED team for data management; J von Schreeb (associate professor, Karolinska Institute), M Ledecq (surgical head of mission, Médecins Sans Frontières, Syria), Olivier Degomme (scientific director, International Centre of Reproductive Health, Ghent University), and Chiara Altare (CRED research fellow) for providing comments and insights on previous versions of this manuscript.

Contributors and sources: DG and JMR designed the research; AFD and JMR analysed the data; DG, JMR, and MH wrote the first draft of the manuscript; all authors contributed to the interpretation of the results and the writing of the manuscript. DG is the guarantor.

Competing interests: We have read and understood BMJ policy on declaration of interests and declare the following: JMR is funded by EU FP7 project Grant Agreement 283201 (emBRACE-Building resilience amongst communities in Europe) and LL is funded by the Royal Institute of International Affairs (Chatham House) and by EU FP7 Project
Agreement 607960 (CAERUS-Evidence based policy for post-crisis stability: bridging the gap). LL also receives funding from the UK Ministry of Justice as a Medical Member of the Tribunal Appeal Service addressing UK health related Social Security benefits, but this has no relationship to this study. All authors have completed the ICMJE uniform disclosure form. The authors have no financial relationships with any organisations that might have an interest in the submitted work in the previous three years, no other relationships or activities that could appear to have influenced the submitted work.

1 World Health Organization. Syrian Arab Republic: WHO statistical profile. Jan 2015. www. who.int/gho/countries/syr.pdf?ua $=1$.

2 Coutts A, Fouad FM, Abbara A, Sibai AM, Sahloul Z, Blanchet K. Responding to the Syrian health crisis: the need for data and research. Lancet Respir Med 2015;3:e8-9.

3 World Health Organization. Syrian Arab Republic: WHO response to the conflict in Syria. Situation Report \#4. Jun 2014. www.emro.who.int/images/stories/syria/SituationReport 20140615.pdf?ua $=1$.

4 World Health Organization. Regional Situation Report. Jan 2015. www.who.int/hac/crises syr/sitreps/syria regional health sitrep january2015.pdf?ua $=1$.

5 Baker E, Brown W. Physicians for Human Rights. Doctors in the Crosshairs: four years of attacks on healthcare in Syria. March 2015. https://s3.amazonaws.com/PHR_Reports/ doctors-in-the-crosshairs.pdf.

6 Hicks MH, Dardagan H, Guerrero Serdán G, Bagnall PM, Sloboda JA, Spagat M. The weapons that kill civilians-deaths of children and noncombatants in Iraq, 2003-2008. N Engl J Med 2009;360:1585-8.

7 UN Office of the High Commissioner for Human Rights.Convention on the rights of the child. 1989. www.ohchr.org/en/professionalinterest/pages/crc.aspx.

8 Hicks MH, Spagat M. The dirty war index: a public health and human rights tool for examining and monitoring armed conflict outcomes. PLoS Med 2008;5:e243.

9 International Committee of the Red Cross. Explosive weapons in populated areas. www. icrc.org/en/explosive-weapons-populated-areas.

10 Price M, Gohdes A, Ball P. Updated statistical analysis of documentation of killings in the Syrian Arab Republic. Commissioned by the UN High Commissioner for Human Rights. Aug 2014. www.ohchr.org/Documents/Countries/SY/HRDAGUpdatedReportAug2014. pdf.

11 Iraq Family Health Survey Study Group, Alkhuzai AH, Ahmad IJ, et al. Violence-related mortality in Iraq from 2002 to 2006. N Engl J Med 2008:358:484-93.

12 Working Group for Mortality Estimation in Emergencies. Wanted: studies on mortality estimation methods for humanitarian emergencies, suggestions for future research. Emerg Themes Epidemiol 2008;4:9.

13 Guha-Sapir D, van Panhuis WG, Degomme O, Teran V. Civil conflicts in four African countries: a five-year review of trends in nutrition and mortality. Epidemiol Rev 2005;27:67-77.

14 Altare C, Guha-Sapir D. The complex emergency database: a global repository of small-scale surveys on nutrition, health and mortality. PLOS ONE 2014;9:e109022.

15 Hicks MH, Dardagan H, Guerrero Serdán G, Bagnall PM, Sloboda JA, Spagat M. Violent deaths of Iraqi civilians, 2003-2008: analysis by perpetrator, weapon, time, and location. PLoS Med 2011;8: e1000415.

16 Mujkic A, Peek-Asa C, Young T, Rodin U. Effect of war on weapon-related deaths in Croatian children and youth. Arch Pediatr Adolesc Med 2008:162:140-4

17 Kuzman M, Tomić B, Stevanović R, Ljubičić M, Katalinić D, Rodin U. Fatalities in the War in Croatia, 1991 and 1992. Underlying and external causes of death. JAMA 1993;270:626-8.

18 United Nations Office of the High Commissioner for Human Rights. Independent international commission of inquiry on the Syrian Arab Republic. 9th report of commission of inquiry on Syria-A/HRC/28/69. Feb 2015. www.ohchr.org/EN/HRBodies/HRC/IICISyria/ Pages/IndependentInternationalCommission.aspx.

19 Dardagan H, Salama H. Stolen futures. The hidden toll of child casualties in Syria. Nov 2013. www.everycasualty.org/downloads/reports/Stolen-Futures.pdf.

20 Violations Documentation Center in Syria. www.vdc-sy.info/index.php/en/about.

21 Slim H. Killing civilians: method, madness and morality in war. Hurst \& Company, 2007.

22 Carpenter RC. Recognizing gender-based violence against civilian men and boys in conflict situations. Secur Dialog 2006;37:83-103.

23 Landmine Action. Explosive violence: the problem of explosive weapons.2009. www.inew. org/site/wp-content/uploads/2011/06/Explosive-violence.pdf.

24 Hicks MH, Dardagan H, Bagnall PM, Spagat M, Sloboda JA. Casualties in civilians and coalition soldiers from suicide bombings in Iraq, 2003-10: a descriptive study. Lancet 2011:378:906-14.

25 Oxfam. Failing Syria. Assessing the impact of UN Security Council resolutions in protecting and assisting civilians in Syria. Mar 2015. www.oxfam.org/sites/www.oxfam.org/files/file_ attachments/bp-failing-syria-unsc-resolution-120315-en1.pdf.

Accepted: 11 August 2015

Cite this as: BMJ 2015;351:h4736

(c) BMJ Publishing Group Ltd 2015 


\section{Key messages}

Children are more likely to be fatal victims of air bombardments, shells, and ground level explosives than men or women Women were the second most likely to die due to explosive weapons. Men were mostly killed by shootings and executions Air attacks and explosive weapons in populated areas should be prohibited or systematically monitored to demonstrate civilian protection Likelihoods for child deaths from air bombardments, shells, and ground level explosives were equal or higher than those caused by chemical weapons and should receive equal international condemnation and control

\section{Figures}

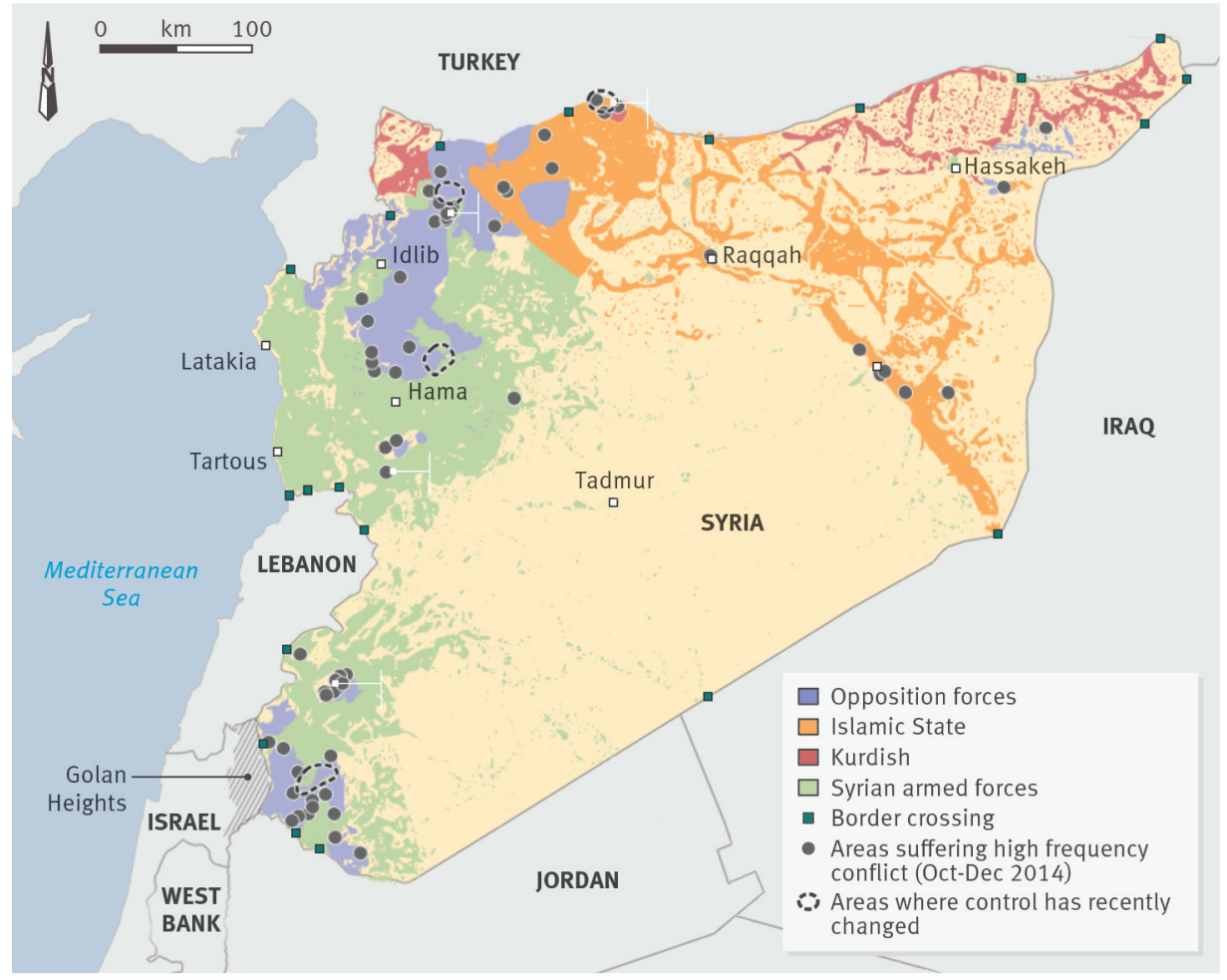

Fig 1 Areas controlled by different factions in the Syrian conflict. Source: BBC

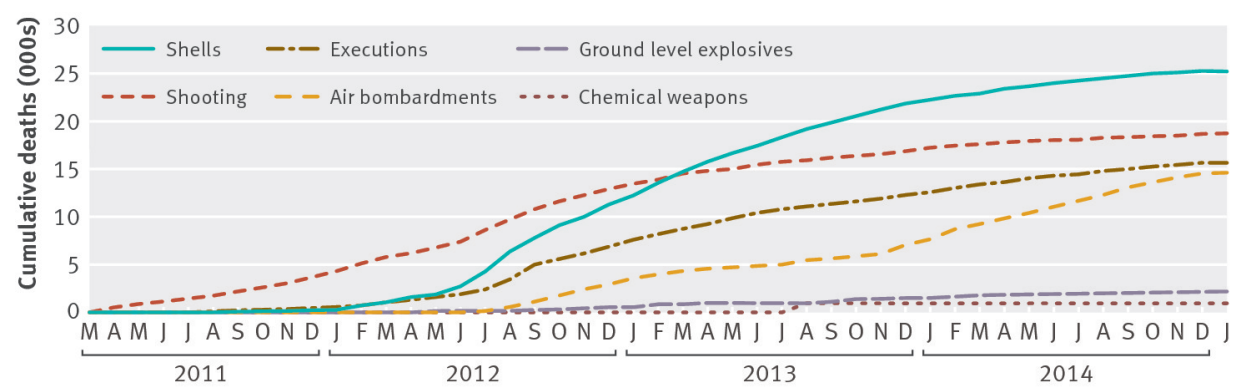

Fig 2 Cumulative deaths by time and weapon type among civilians in NSAG controlled areas 

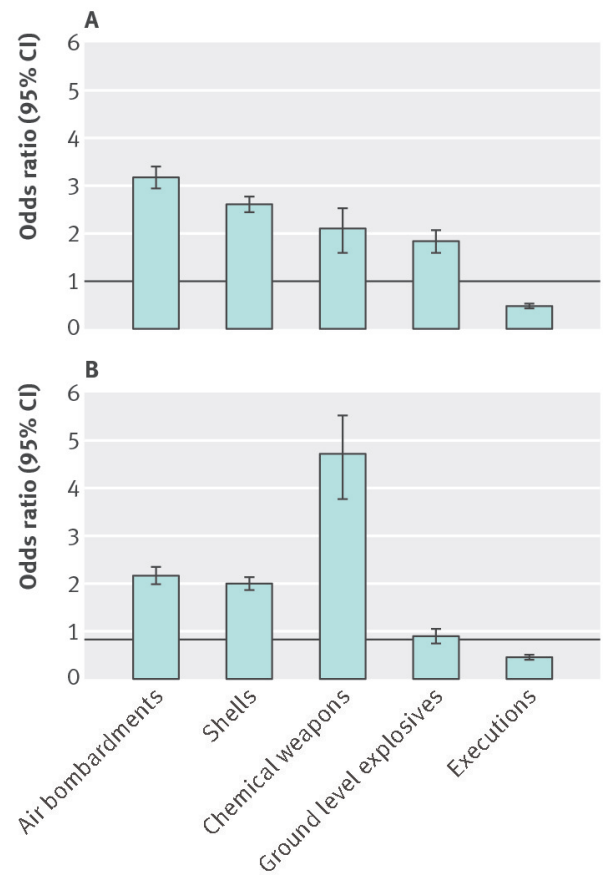

Fig 3 Odds ratios of deaths by weapon types in civilian children (A) and women (B) in NSAG controlled areas. Reference category for weapons is shooting. Reference category for children and women is men

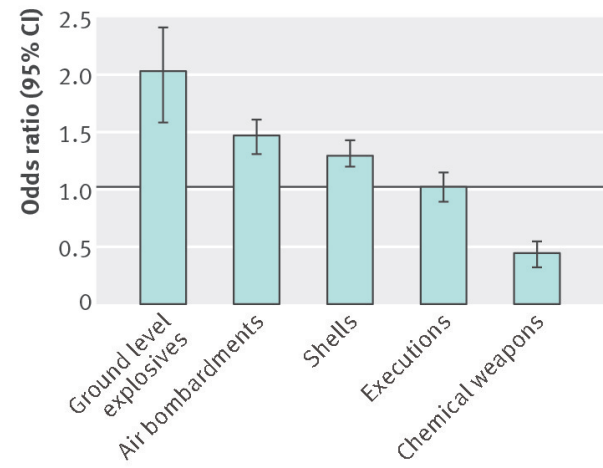

Fig 4 Odds ratios of deaths by weapon types in civilian children compared with women in NSAG controlled areas. Reference category for weapons is shooting 